A member of APSA for nearly 20 years, Dr. Lee Ann Fujii was a wellrespected associate professor at the University of Toronto researching political violence, ethnicity and race, African politics, and field methods when she passed away unexpectedly last year. Now, a group of political scientists are coming together to establish a memorial fund that honors her life and contributions to the discipline.

"Lee Ann Fujii and I became fast friends, colleagues, and disciplinary comrades soon after we met at the 2004 Institute for Qualitative and Multi-Method Research," said Dr. Robin Turner, associate professor at Butler University. "[She] was a brilliant scholar whose methodological work raises a host of questions with no easy answers" (Turner 2018, 48-49).

Those who had the pleasure of knowing Lee Ann described her as a dear educator and colleague dedicated to supporting the next generation. Many of Lee Ann's mentees went on to have their own successful careers in political science, including Dr. Nick Smith, assistant professor at The City College of New York. "Lee Ann was an extraordinary mentor to many junior faculty and graduate students across the discipline, so finding a way to honor her legacy is important. Just as she was devoted to mentoring others, she was also committed to diversifying the discipline."

As a tribute to Lee Ann, Robin, Nick, and others are undertaking an effort with APSA to expand the number of available travel grants for APSA Minority Fellows. The APSA Minority Fellowship Program, which is celebrating its 5 oth anniversary this year, is a fellowship competition for individuals from underrepresented backgrounds applying to or in the early stages of doctoral programs in political science.

The APSA Lee Ann Fujii Minority Fellowship Program Travel Grants support fellows' participation in APSA's meetings so that they can engage in research, professional development, mentoring, and collaboration. Travel grants play a critical role in ensuring that APSA's Annual Meetings continue to be enriched by scholars regardless of their financial abilities.
Through donor support, APSA Lee Ann Fujii Minority Fellowship Program Travel Grants will enable more underrepresented, early-career scholars to participate in valuable training, educational, and networking activities alongside thousands of peers and established professionals-an opportunity that may otherwise not be available to them because of the constraints and demands on the financial resources of emerging scholars.

Already, a large number of gifts have poured in from interested donors since the effort began to fund APSA Lee Ann Fujii Minority Fellowship Program Travel Grants over the next five years and starting with the 2019APSA Annual Meeting in Washington, DC. "Seeing how many of Lee Ann's friends, colleagues, and family members have contributed to this effort shows the profound impact she has had on others and our commitment to perpetuate Lee Ann's work," said Nick.

Members of Lee Ann's family, including her brothers, Jeff and Carey Fujii, and sisterin-law Josephine (Carey's wife), said that the family is both proud and in awe of Lee Ann's many accomplishments. Remembering Lee Ann's playful spirit, brother Carey shared this personal story with APSA:

"Lee Ann was competitive growing up, and nowhere was this more evident than family game night when we played Scrabble. I have used all seven tiles maybe a dozen times in my whole Scrabble-playing career, but for Lee Ann, it happened at least once every time we played. Being the ever-supportive older brother, I would wait until Lee Ann was counting her score, then 'bump' the board such that the tiles got out of place, then calmly declare the game a draw with nowinner. This would trigger now uncontrollable laughter in Lee Ann for at least five minutes, after which she would ask: 'Play again?"'

To make a contribution to the APSA-Lee Ann Fujii Minority Fellowship Program Travel Grant, please visit www.apsanet.org/ $\mathrm{mfp} /$ travelgrant $\mathbf{}$

Adapted from the PS Now press release.

Turner, Robin L. 2018. "Remembering Lee Ann in South Africa: Meta-Data and Reflexive Research Practice." Qualitative and Multi-Method Research 16 (1): 48-50.

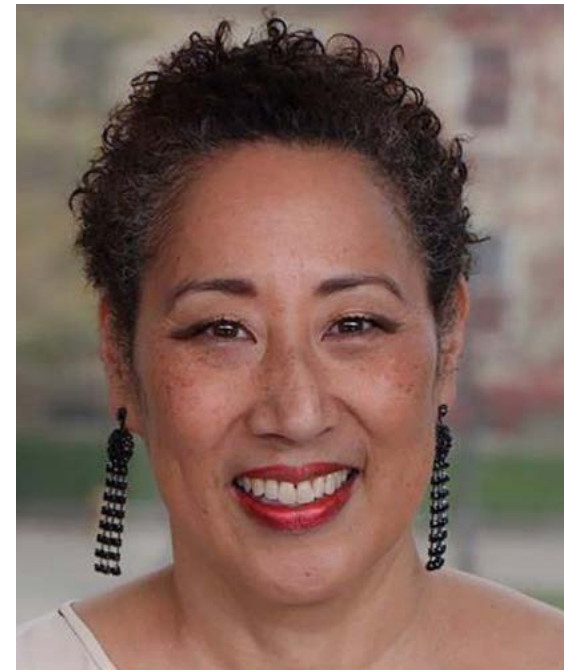

2019 CLASS OF APSA LEE ANN FUJII MINORITY FELLOWSHIP PROGRAM TRAVEL GRANT RECIPIENTS

Estefania Castaneda Perez, graduate student, University of California, Los Angeles (MFP 2016-17)

Safia Farole, lecturer, University of California, Los Angeles (MFP 2011 - 2012)

Gregory Leslie, graduate student, University of California, Los Angeles (MFP spring 2017)

David Monda, graduate student, Graduate Center, City University of New York (MFP spring 2018)

Oanh Nguyen, graduate student, University of Minnesota (MFP spring 2017)

Tanika Raychaudhuri, PhD candidate, Princeton University (MFP 2016 - 17)

Liana Reyes-Reardon, graduate student, Rice University (MFP 2017-18)

Richie Romero, graduate student, Arizona State University (MFP 2018 - 19)

Tiffany Willoughby-Herard, associate professor, University of California, Irvine (MFP 1995 - 96) 


\section{RBSI iPoster Presentations}

$\Lambda$

t each APSA Annual Meeting, the current cycle of Ralphe Bunche Summer Institute (RBSI) Scholars have the opportunity to present their research in the form of iPosters and engage in educational and professional development activities. The iPosters are part of the APSA Exhibit Hall. This year's presentations occured on Saturday, August 31. The undergraduate RBSI scholars who presented focused on a widevariety of research, including:

\section{A New Tool for Mobilization? The Effects of Social Media Use on Youth Voter Turnout \\ Silvia Ferrer, University of California, Riverside}

The Politics of Prison: The Intersection of Educational Disparities and Length of Sentencing

Jakini Auset Sharmane Ingram, The Ohio State University

Female Representation in Local Governments and Reports of Rape: Observing US-Mexico Border Communities in the United States

Willow Lopez, University of Dayton

The Politics of Toilets: Exploring Sanitation in Haiti

Maria Martinez, University of Louisville.

Black Politics: Congresspeople, Constituencies, and Accountability

Joshua Nnaji, Wake Forest University

Somos Todas: Effects of Social Networks and Group Identity on Women's Approval of Protest Politics in Argentina

Ignangeli Salinas-Muniz, University of Puerto Rico

Ideological Uncertainty: Black Politics and the LiberalConservative Continuum

Pyar Seth, Trinity University

The Ralphe Bunche Summer Institute Program (RBSI) is an annual, intensive five-week program held at Duke University. It is designed to introduce the world of doctoral study in political science to undergraduate students from underrepresented racial and ethnic groups or those interested in broadening participation in political science and pursuing scholarship on issues affecting underrepresented groups or issues of tribal sovereignty and governance. Participants in the RBSI are drawn from a competitive national applicant pool. To learn more about the RBSI Program, visit: https://www.apsanet.org/rbsi -

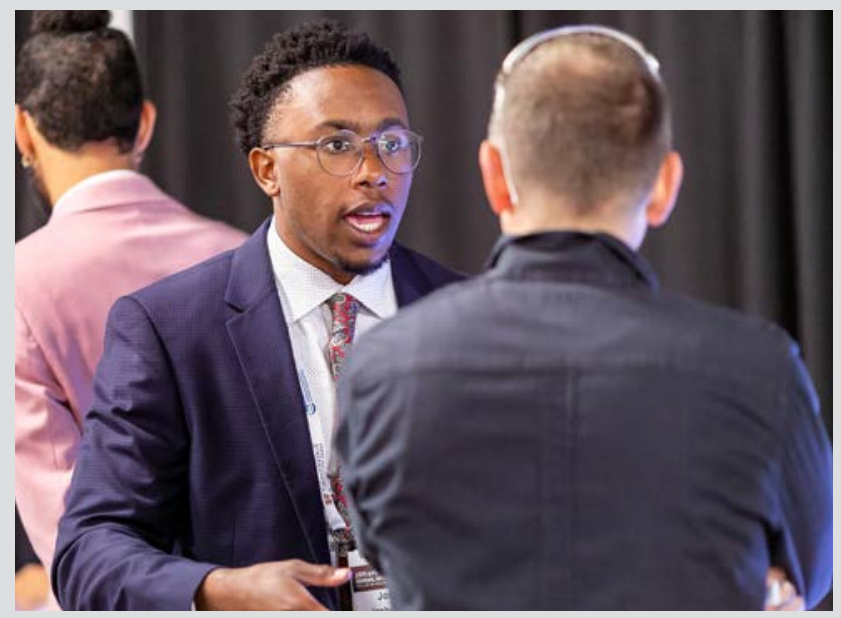

Joshua Nnaji, Wake Forest University (left) explains his project "Black Politics: Congresspeople, Constituencies, and Accountability" to an attendee.

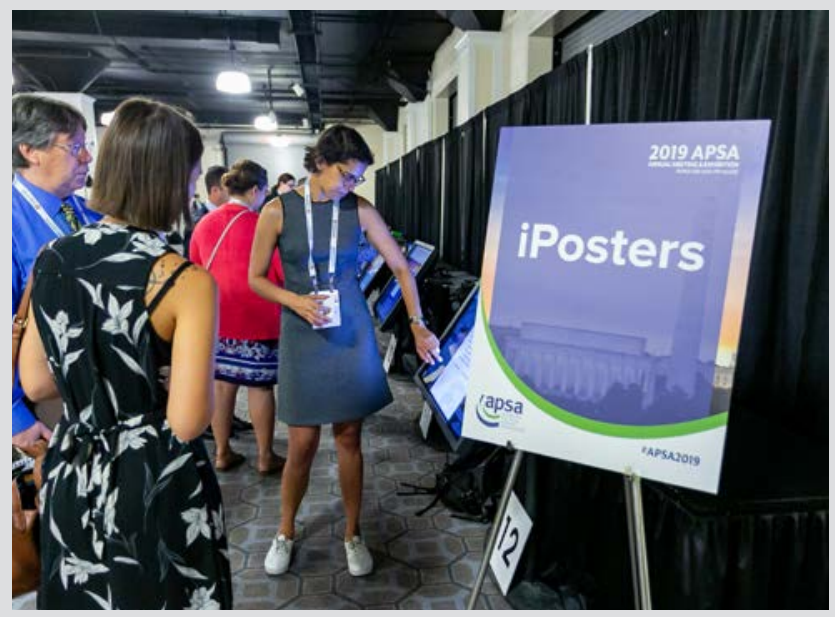

iPosters allowed RBSI scholars to present interactive, multi-media presentations at the 2019 Annual Meeting.

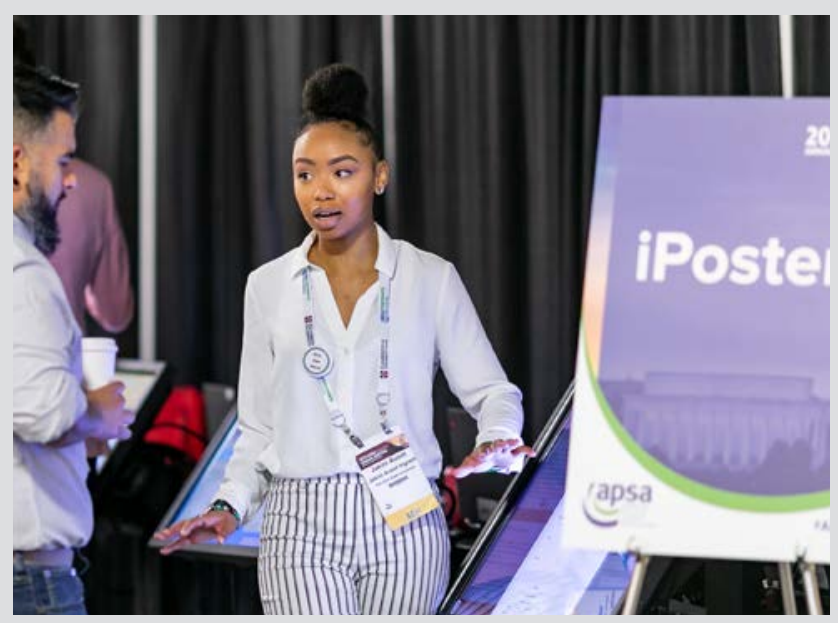

Jakini Auset Ingram, The Ohio State University (left) speaks with an attendee about her project: "The Politics of Prison: The Intersection of Educational Disparities and Length of Sentencing." 